\title{
PENGARUH K3 PADA MOTIVASI DAN KINERJA KARYAWAN (Studi Pada Karyawan PT. YTL - Paiton- Jawa Timur)
}

\author{
Maharani Ikaningtyas ${ }^{1}$, Mochammad Al Musadieq ${ }^{2}$, Arik Prasetya ${ }^{3}$ \\ Fakultas Ilmu Administrasi, Universitas Brawijaya, Malang, Indonesia \\ Email: maharaniika602@gmail.com ${ }^{1)}$, musadieqfia@ub.ac.id ${ }^{2)}$, arik_p_fia@ub.ac.id ${ }^{3)}$
}

\begin{abstract}
The growth of the company can be seen from how big the employee could be contribute to the company. This issue could been know form the growth of Human Resources (HR) and also the results of work that can complete the company targets. Occupatiional Safety and Health Program consists of guarantees of work accidents and occupational health that are expected to be good for employee performanc. This research is an explanatory type of research. Data collection can be used using a questionnaire. The research uses probability sampling technique that is proportional random sampling. The number of samples obtained was 78 respondents from the calculation of Slovin. analysis data used the path analysis method. The resultts of this study prove that work safety is significant for work motivation's. Work health is positive to work motivatiion. As well as positive and significant work motivation on employee performance.
\end{abstract}

Keywords: Occuppational safety and health, Incentives, Work Motivation, and Employee Perrformance

\begin{abstract}
ABSTRAKSI
Perkembangan suatu perusahaan dapat dilihat dari seberapa besar kontribusi para pekerja yang sudah dilakukan untuk perusahaan tersebut. Hal ini disertai dengan berkembangnya tenaga Sumber Daya Manusia dan hasil kerja yang dapat memenuhi target sebuah perusahaan. program K3 untuk jaminan resiko terjadinya kecelakaan saat bekerja dan kesehatan karyawan dalam bekerja diharapkan memiliki pengaruh yang baik terhadap kinerja para karyawan. Penelitian ini diilakukan agar dapat mengetahui pengaruh Keselamatan dam Kesehatan Kerja, serta Motivasi pada Kinerja pegawai. Jenis Penelitian yang telah dilakukan merupakan jenis penelitian explanatory research. Pengumpulan data yang didapat dengan menggunakan penyebaran kuesioner. Peneliti menggunakan teknik probability sampling yaitu proportionate random sampling. Diperoleh jumlah sampel sebanyak 78 responden dari perhitungan rumus slovin. path analysis adalah metode yang telah di gunakan pada research ini. Penelitian ini menjelaskan bahwa K3 signfikan terhadap motivasi kerja pegawai. Kemudian motivasi juga berpengaruh pada hasil kerja karyawan.
\end{abstract}

Kata Kunci: K3, Motivasi, Kinerja 


\section{PENDAHULUAN}

Tingginya volume kompetisi dalam dunia bisnis pada saat ini, memaksa perusahaan perusahaan untuk mengoptimalkan dan memaksimalkan segenap Sumber Daya Manusia (SDM) yang dimiliki supaya mencapai visi misi perusahaan tersebut. Keberhasilan sebuah perusahaan diperoleh dari kinerja yang mkasimal dari para pekerjanya.

Jamiinan Keselamatan Kesehatan Kerja yang diiberikan di trmpat kerja terhadap para pekerja adalah suatu hal yang sangat dibutuhkan. Mengingat tingkat kecelakaan kerja di Negara Indonesia masih sangat tinggi. Pada perhitungan data di Disnakertransduk Provinsi Jawa Timur, jumlah kasus kecelakaan kerja selama tahun 2017 cukup tinggi, yakni mencapai 20.466 insiden. Seluruh kecelakaan itu terjadi di area dalam dan luar lingkungan kerja (kecelakaan kerja yang melibatkan pekerja). Artinya, jika dirata-rata, dalam sehari sedikitnya ada 56 kasus. Sebanyak 330 pekerja meninggal karena peristiwa tersebut. Hasil catatan dari Disnakertransduk, sebanyak 7.079 insiden berupa kasus kecelakaan di luar kerja. Yakni, kecelakaan lalu lintas, baik yang dialami para pekerja ketika berangkat maupun pulang kerja. Total ada 13.387 kejadian. Mayoritas terjadi di industri-industri yang melibatkan alat berat. (Jawa Pos, 12 Januari 2018).

Keselamatan kerja memang sangat dibutuhkan karyawan agar meminimalisir terjadinya kecelakaan yang tidak jarang dapat terjadi diluar kesiapan pekerja dalam melindungi dirinya. Namun faktor kesehatan juga merupakan salah satu perihal yang tidak boleh diabaikan seorang karyawan perusahaan. sebuah perusahaan, adanya lingkungan kerja yang kondusif merupakan pendukung yang dapat menunjang kenyamanan tempat bagi karyawannya dalam bekerjja. Kesehatan merupakan kuncii setiap individu tenaga kerja supaya dapat bekerja dengan maksimal dan baik sehingga menimbulkan semangat kerja dan kenyamanan karyawan dalam bekerja.

Kepedulian perusahaan pada keselamatan kesehatan kerja dapat meniingkatkan motivasi kerja para pekerja. Motiivasi kerja sangat erat kaitannya terhadap kinerja karyawan. Dimana hal tersebut mampu memberikan kontribusi antara karyawan terhadap perusahaan. Motivasi adalah perihal yang sangat dibutuhkan dalam individu karyawan guna memberikan kontribusi yang baik terhadap pencapaian tujuan perusahaan. Apabila karyawan tidak memiliki motivasi dalam bekerja maka akan terjadi timbulnya perasaan tidak semangat dalam bekerja. Pengaruh (K3) terhadap motivasi kerja juga didukung oleh peneliti terdahulu Dewi (2014), Itsalis et al. (2016), Mutiarasari et al. (2017), Rukhyanti (2007), Santoso (2017), dan Wijayanto (2009).

PT. YTL merupakan perusahaan Pembangkit Listrik Tenaga Uap (PLTU) swasta terbesar kedua di Indonesia bergerak pada bidang pengoperasian dan perawatan PLTU pada Unit 5 dan Unit 6 dengan bahan utamanya adalah bakar batubara. Pada proses kerjanya, karyawan menggunakan mesin-mesin dan peralatan berat, yang dapat menyebabkan adanya potensi bahaya serta dapat memberikan ancaman keselamatan serta kesehatan karyawannya. Mengacu pada uraian yang telah dijabarkan, maka tujuan dari artikel ini guna mengetahui adanya pengaruh keselamatan serta kesehatan kerja, serta Motivasi kerja terhadap Kinerja pegawai.

\section{KAJIAN PUSTAKA}

\section{Keselamatan Kerja}

Merupakan sebuah kondisi selamat yang bebas dari resiko kecelakaan saat bekerja serta munculnya kerusakan dimana mencakup tentang kondisi tempat kerja, kondisi mesin, peralatan kerja, dan kondisi para pekerja. Maka hal tersebut bertujuan untuk mencegah kerusakan mesin yang dapat membahayakan operator (Hasibuan, 2011).

\section{Kesehatan Kerja}

merupakan hal penting dan perlu diperhatikan oleh perusahaan terhadap para pekerjanya. Hal tersebut dikarenakan dengan adanya program kesehatan yang baik akan menguntungkan para karyawan secara material. kesehatan kerja adalah jaminan untuk para pekerja pada saat melakukan pekerjaan di tempat kerja. 


\section{Motivasi}

Motivasi kerja sering digunakan untuk menyebutkan motivasi dalam lingkungan kerja. Dalam manajemen sering dipakai untuk menerangkan motivasi yang ada kaitannya dengan pekerjaan. Kunci untuk memahami proses motivasi bergantung pada pengertian dan hubungan antara dorongan, kebutuhan,dan insentiv.

Robbins (2003) mengemukakan bahwa motivasi adalah suatu proses yang berperan iintensitas, arah, serta lamanya berlangsung upaya individu kearah pencapaian sasaran tiga, unsur kunci dalam definisi di atas adalah intensitas, arah dan berlangsung lama.

\section{Kinerja Karyawan}

Menurut Mangkuprawita dan Hubies (2007), kinerja adalah hasil dari proses pekerjaan karyawan secara terencana pada waktu dan tempat serta organisasi yang bersangkutan.

Selanjutnya pendapat dari As'ad (2000) berpendapat bahwa kinerja karyawan diketahui dari ukuran sejauhmana keberhasilan pekerja dalam melakukan tugas pekerjaannya demi memenuhi target yang telah ditentukan.

\section{METODE PENELITIAN}

Explanatory adalah jenis penelitian yang telah dilakukan pada penelitian ini. Serta penelitian ini termasuk jenis data penelitian kuantitatif. Jenis data penelitian yang di lakukan termasuk dalam kategori data primer. Dalam menentukan sampel, digunakan teknik probability sampling yaitu proportionate random sampling. Selanjutnya jumlah sampel yag telah diperoleh sebanyak 78 responden. penelitian ini dianalisis dengan menggunakan teknik analisis jalur dengan program software SPSS versi 22.0, sehingga dapat mempermudah mengelola data yang berbentuk angka statistik dan kemudian dapat diambil kesimpulannya.
HASIL DAN PEMBAHASAN

Tabel 1. Terdapat Pengaruh Secara Langsung dan Secara Tidak Langsung

\begin{tabular}{lclc}
\hline $\begin{array}{l}\text { Hubungan } \\
\text { variabel }\end{array}$ & \multicolumn{3}{c}{ Pengaruh } \\
\cline { 2 - 4 } & Langsung & $\begin{array}{c}\text { Tidak } \\
\text { Langsung }\end{array}$ & Total \\
\hline $\mathrm{X} 1-\mathrm{Y} 1$ & 0,223 & - & 0,223 \\
$\mathrm{X} 1-\mathrm{Y} 2$ & 0,172 & - & 0,172 \\
$\mathrm{X} 2-\mathrm{Y} 1$ & 0,504 & - & 0,504 \\
$\mathrm{X} 2-\mathrm{Y} 2$ & 0,478 & - & 0,478 \\
$\mathrm{Y} 1-\mathrm{Y} 2$ & 0,362 & - & 0,362 \\
$\mathrm{X} 1-\mathrm{Y} 1-\mathrm{Y} 2$ & - & 0,080 & 0,080 \\
$\mathrm{X} 2-\mathrm{Y} 1-\mathrm{Y} 2$ & - & 0,182 & 0,182 \\
\hline
\end{tabular}

Hasil dari perhitungan statistic, menunjukkan bahwa $\mathrm{X} 1$ memiliki pengaruh positif terhadap Y1 dengan nilai sebesar 0,223. X1 memiliki dampak baik pada Kinerja Karyawan dengan nilai koefisien sebesar 0,172. kemudian Kesehatan Kerja berpengaruh positif pada variabel Motivasi Kerja dengan nilai yaitu 0,504. Kesehatan Kerja memiliki pengaruh positif pada Kinerja Karyawan, diketahui dengan nilai koefisien 0,478. Dan selanjutnya Motivasi Kerja memiliki pengaruh signifikan pada variabel Kinerja Karyawan dengan nilai koefisien sebesar 0,362 .

koefisien determinasi $\left(\mathrm{r}^{2}\right)$ digunakan untuk Pengujian ketetapan model dengan menggunakan total dari dua persamaan. Persamaan pertama diiperoleh nilai $\mathrm{r}^{2} 0,448$ dan persamaan 2 (kedua) diperoleh $\mathrm{r}^{2}$ sebesar 0,789. Di bawah ini merupakan ketetapan model dengan rumus $\mathrm{r}^{2}$ :

$$
\begin{aligned}
& r^{2}=1-\left(1-r^{2} 1\right)\left(1-r^{2} 2\right) \\
&=1-(1-0,448)(1-0,789) \\
&=1-(0,552)(0,211) \\
&=0,883 \text { atau } 88,3 \%
\end{aligned}
$$

Hasil perhitungan ketetapan model sebesar $88,3 \%$, hal tersebut menjelaskan bahwa kontribusi model untuk menjelaskan hubungan struktural dari variabel yang diteliti yaitu sebesar $88,3 \%$. 
Hasil Pengujian Analisis Jalur

Koefisien Jalur Pertama

Tabel 2 Uji Koefisiensi Jalur Pertama

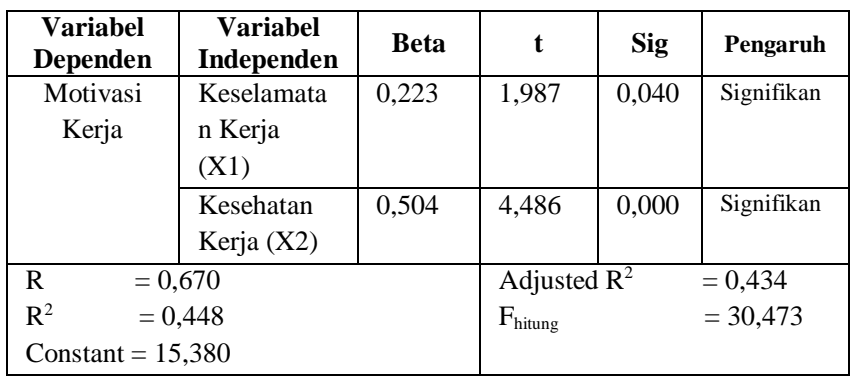

Sumber: Data primer diolah SPSS, 2018

Angka konstan (a) diartikan sebagai nilai yang muncul pada variable dependen jika tidak ada variable independen. Sehingga, apabila tak ada variabel $\mathrm{X} 1$, dan $\mathrm{X} 2$, maka $\mathrm{Y} 1$ sendiri memiliki nilai 15,380 .

Berdasarkan Tabel 2 terdapat pengaruh variabel X1 dan X2 terhadap Y1. Dari hasil uji koefisien jalur pada Tabel. 2 didapatkan nilaii Adjusted $\mathrm{R}^{2}$ sebesar 0,434 .

\section{Koefisien Jalur Kedua}

Tabel 3 Hasil Uji Koefisien Jalur Kedua

\begin{tabular}{|c|c|c|c|c|c|}
\hline $\begin{array}{c}\text { Variabel } \\
\text { Depende } \\
\mathbf{n}\end{array}$ & $\begin{array}{c}\text { Variabel } \\
\text { Independen }\end{array}$ & Beta & $\mathbf{t}$ & Sig & Pengaruh \\
\hline \multirow[t]{3}{*}{$\begin{array}{c}\text { Kinerja } \\
\text { (Y2) }\end{array}$} & $\begin{array}{c}\text { Keselamatan } \\
\text { (X1) }\end{array}$ & 0,172 & 2,405 & 0,019 & Signifikan \\
\hline & $\begin{array}{l}\text { Kesehatan } \\
\text { Kerja (X2) }\end{array}$ & 0,478 & 6,081 & 0,000 & Signifikan \\
\hline & $\begin{array}{c}\text { Motivasi } \\
\text { Kerja (Y1) }\end{array}$ & 0,362 & 5,044 & 0.000 & Signifikan \\
\hline $\begin{array}{l}\mathrm{R} \\
\mathrm{R}^{2} \\
\text { Constant }=\end{array}$ & $\begin{array}{l}888 \\
0,789 \\
334\end{array}$ & & $\begin{array}{l}\text { Adjus } \\
\text { F }_{\text {hitung }}\end{array}$ & $\mathrm{d} \mathrm{R}^{2}$ & $\begin{array}{l}=0,781 \\
=92,376\end{array}$ \\
\hline
\end{tabular}

Sumber: Data primer diolah SPSS, 2018

Angka konstan (a) diartikan sebagai nilai yang muncul pada variabel dependen jika tidak ada variabel independen. Sehingga, apabila tak ada variable X1 , X2, dan Y1 maka Y2 mempunyai nilai 2,334 .

Hasil dari Table 3 diiketahui hubungan yang signivikan antara variable $\mathrm{X} 1, \mathrm{X} 2, \mathrm{Y} 1$ dan Y2. Dari hasil uji koefisien pada Tabel. 3 didapatkan nilai Adjusted $\mathrm{R}^{2}$ sebesar 0,781. Artinya bahwa $78,1 \%$ kinerja pegawai dipengaruhi oleh variabel independen, yaitu Keselamatan Kerja serta Kesehatan Kerja.

Berdasarkan hasil pengujian analisis jalur dari koefisien jalur pertama dan jalur kedua, maka kelengkapan model analisis jalur dapat dilihat pada gambar di bawah ini:

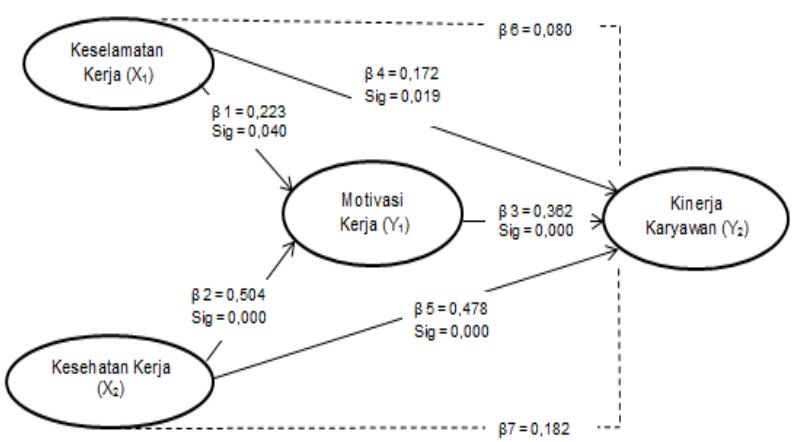

Gambar 1: Model Hasil Path Analysis

Keselamatan Kerja berpengaruh langsung terhadap variabel Motivasi

Perhitungan hasil uji statistik dapat diketahui bawah keselamatan kerja ber pengaruh yang signifikan terhadap variable motivasi diketahui nilai koefisiensi determinan sebesar 0,223 . Hasil tersebut juga sejalan dengan penelitian Rukhyanti (2007) juga menyatakan bahwa jaminan keselamatan kerja dipandang sebagai salah satu faktor peningkatan motivasi kerja karyawan. Pengaruh Keselamatan Kerja yang terdiri dari Faktor manusia, Faktor materialnya, Faktor bahaya dan Faktor yang dihadapi terhadap Motivasi.

\section{Variable Kesehatan Kerja memiliki pengaruh signifikan pada variable motivasi kerja}

Dilakukan perhitungan uji statistik, diketahui hasilnya menunjukkan bahwa kesehatan kerja berpengaruh signifikan pada variable motivasi kerja dan dapat diketahui nilai dari koefisiensi determinan sebesar 0,504. Hal tersebut memiliki kesamaan dengan penelitian yang sudah diteliti oleh penelitian Munandarr (2014), diketahui bahwa Kesehatan kerja adalah variable yang mempunyai hubungan secara signifikan pada variabel Motivasi Kerja. 


\section{Keselamaatan Kerja berpengaruh Langsung pada Kinerja Karyawan}

Perhitungan dari hasil analisis yang telah menguji pengaruhnya variabel keselamatan pada kinerja diketahui bahwa X1 secara positiv dan signifikkan memiliki pengaruh pada kinerja karyawan dengan nilai koefisiensi yaitu 0,172 . Jadi dapat dikatakan hasil penelitian ini juga mendukung empiris yang telah dilakukan peneliti Amelia pada tahun 2017, ditemukan hubungan yang searah serta positif antara Keselamatan Kerja terhadap Kinerja pegawai.

\section{Pengaruh Kesehatan Kerja terhadap Kinerja Karyawan}

Dari analisis inferensial yang telah diketahui bahwa kesehatan kerja berpengaruh terhadap kinerja karyawan secara signifikan memiliki pengaruh yang baik terhadap kinerja karyawan. Diketahui bahwa nilai dari perhitungan determinan yaitu 0,478 . penelitian ini juga didukung oleh empiris yang telah dilakukan peneliti Maryjoan dan Tom pada tahun 2016, bahwa ditemukan hubungan yang searah antara variabel kesehatan kerja dengan kinerja pegawai.

\section{Pengaruh Motivasi kerja terhadap Kinerja Karyawan}

Dijelaskan bahwa analisis inferensial yang menguji pengaruh motivasii kerja terhadap kinerja karyawan menyebutkan bahwa motivasi kerja secara positif berpengaruh terhadap kinerja karyawan dengan nilai koefisiensinya 0,362 . Hal tersebut didukung oleh penelitiian yang dilakukan Prasetyo (2014). Hasil penelitian tersebut menunjukkan besarnya nilai koefisien beta yang telah dihitung antara motivasi terhadap kinerja karyawan yaitu sebesar 0.747 atau $74,7 \%$ dengan nilai signifikan 0,000 . Perhitungan tersebut telah memenuhi syarat bahwa sig $\mathrm{t}<\operatorname{sig} \alpha$, yaitu $0,000<$ 0,05 . Sehingga dapat disimpulkan bahwa motivasi kerja berpengaruh signifikan terhadap kinerja karyawan.
Melalui Motivasi Kerja, Variabel Keselamatan Kerja memiliki pengaruiih secara tidak langsung terhadap kinerja karyawan

Penelitian ini telah diketahui bahwa terdapat pengaruh yang tidak langsung antara variabel keselamatan kerja terhadap kinerja pegawai melalui variabel motivasi kerja dengan penjelasan di bawah ini::

1. Perhitungan dari koefisien variabel keselamatan kerja pada motivasi kerja yaitu 0,223 .

2. koefisien jalur variabel $\mathrm{X} 1$ pada $\mathrm{Y} 2$ nilai yang diketahui sebesar 0,172 .

3. Nilai perhitungan jalur yang dimiliki variable keselamatan kerja pada kinerja karyawan melalui variabel motivasi kerja yaitu 0,080.

\section{Melalui Motivasi Kerja, Kesehatan Kerja memiliki pengaruh secara tidak langsung terhadap kinerja karyawan}

1. Diketahui hasil perhitungan jalur koefisien kesehatan kerja terhadap motivasi kerja dengan nilai sebesar 0,504.

2. Perhitungan koefisien jalur kesehatan kerja pada kinerja karyawan yaitu 0,478 .

3. Jalur variable kesehatan kerja terhadap kinerja karyawan melalui motivasi kerja terdapat nilai sebesar 0,182 .

\section{KESIMPULAN DAN SARAN}

\section{Kesimpulan}

Seperti pada pembahasan yang telah diuraikan, kesimpulan yang dapat dijabarkan $\mathrm{X} 1$ mempunyai pengaruh yang searah dan signifikan terhadap motivasi kerja. nilai koefisiensi yang diketahui yaitu 0,223 . kesehatann kerja juga memiliki pengaruh yang signifikan terhadap motivasi kerja dan nilai yang dapat diperoleh adalah 0,504. Variabel motivasi kerja juga memiliki pengaruh yang positif pada variabble $\mathrm{Y} 2$,diketahui dari nilai determinannya sebesar 0,362. Variabel X1 sendiri, memiliki pengaruh signifikan pada kinerja karyawan dengan nilai koefisiensinya yaitu 0,172. Diketahui Selanjutnya, kesehatan kerja diketahui berpengaruh yang searah terhadap variabel kinerja karyawan, dan dengan nilai koefisiensi sebesar 0,478. 
Penjabaran selanjutnya adalah dapat diketahui adanya pengaruh secara tidak langsung pada X1 terhadap Y2 dengan melalui motivasi Y1 dan nilainya sebesar 0,080. Kemudian juga terdapatnya pengaruh tidak langsung antara variable X1 terhadap kinerja karyawan melalui variable $\mathrm{Y} 1$ dengan nilai 0,182 .

\section{Saran}

Berdasarkan kesimpulan di atas, maka bebberapa saran yang diiharapkan dapat bermanfaat bagii perusahaan dan juga pihakpihak lain. Diantaranya yaitu:

1. Bagi pembaca diiharapkan hasil penelitian ini dapat di gunakan sbagai bahan acuan bagi peneliti selanjutnya

2. Diketahui bahwa PT. YTL padaa 2014 telah mendapatkan awards pada penerapan SMK3 diketahui bahwa memiliki tingkat pencapaian sebesar 95\% atau dikategorikan memuaskan. Dengan demikian, diharapkan bagi pihak perusahaan dapat mempertahankan.

3. Tetap mempertahankan untuk selalu peduli dalam penggunaan APD (Alat Pelindung Diri) dan atau kelengkapan safety pada saat bekerja.

\section{DAFTAR PUSTAKA}

Amelia. 2017. Pengaruh Keselamatan dan Kesehatan Kerja (K3), Disiplin Kerja dan Lingkungan Kerja Terhadap Kinerja

Karyawan Pada Pt. Asia Citra Industries Tanah Putih, Rokan Hilir.

As'ad, M., 2000. Psikologi Industri, edisi ke$V$. Liberty. Yogyakarta.

Dewi. 2014. Pengaruh Program Keselamatan Dan Kesehatan Kerja Terhadap Motivasi Dan Kinerja Karyawan. Jurnal Administrasi Bisnis (JAB). Vol. 16 No. 1 November 2014.

Hadiguna. (2009). Manajemen Pabrik. Jakarta: Bumi Aksara.
Hasibuan. 2011. Manajemen Personalia dan Sumber Daya Manusia. Penerbit BPFE. Yogyakarta.

Itsalis, Prasetya, Ruhana. 2016. Pengaruh Program Keselamatan Dan Kesehatan Kerja Terhadap Motivasi Kerja Dan Kinerja Karyawan (Studi Pada Karyawan Bagian Produksi PT. Citra Gading Asritama Di Proyek Mall Dinoyo City Malang, Jawa Timur). Jurnal Administrasi Bisnis (JAB), Desember 2016, Vol. 41 No.1.

Mangkuprawita, Sjafri dan Hubeis, Aida Vitalaya. 2007. Managemen Mutu Sumber Daya Manusia. Ghalia Indonesia. Bogor.

Maryjoan And Tom. 2016. Effects Of Industrial Safety And Health On Employees' Job Performance In Selected Cement Companies In Cross River State, Nigeria. International Journal of Business and Management Review, Vol.4, No.3, No. 49-56.

Munandar, Astuti, dan Hakam. 2014. Pengaruh Keselamatan, Kesehatan Kerja (K3) Dan Insentif Terhadap Motivasi Dan Kinerja Karyawan (Studi Pada Pekerja bagian Produksi PT. Sekawan Karyatama Mandiri Sidoarjo). Jurnal Administrasi Bisnis (JAB), Vol. 9 No. 1.

Mutiarasari, Prasetyo, Dan Djudi. 2017. Pengaruh Program Keselamatan Dan Kesehatan Kerja (K3) Serta Lingkungan Kerja Terhadap Motivasi Dan Kinerja Karyawan (Studi Pada Karyawan Pg. Kebon Agung Kabupaten Malang). Jurnal Administrasi Bisnis (JAB), Vol. 47 No. 2.

Robbins, Stephen P. 2003. Perilaku Organisasi. Jilid 1. Diterjemahkan Tim Indeks. PT Indeks Kelompok Gramedia. Jakarta. 
Rukhyanti, Novi. 2007. Pengaruh Penerepan Sistem Manajemen Keselamatan dan Kesehatan Kerja (K3) Terhadap Kinerja Karyawan Melalui Motivasi Pada Perusahaan Industri Garmen di Kawasan Industri Rancaekek". Bandung: STIE STAN Indonesia Mandiri.

Santoso. 2017. Pengaruh Motivasi,

Kompensasi, Kesehatan Dan Keselamatan Kerja Terhadap Kinerja Karyawan. Jurnal Ilmu dan Riset Manajemen, Vol. 6 No. 12.

Wijayanto, Astuti. Utami. 2009. Pengaruh Keselamatan Dan Kesehatan Kerja Terhadap Motivasi Kerja Dan Kinerja Karyawan (Studi Pada Karyawan Pt. Pertamina (Persero) Suplai Dan Distribusi Region V Terminal Bahan Bakar Minyak Malang). 